\title{
Powder injection molding 440C stainless steel
}

\author{
Duxin Li $\cdot$ Haitao Hou $\cdot$ Lianghua Liang $\cdot$ Kun Lee
}

Received: 4 March 2009 /Accepted: 21 October 2009/Published online: 14 March 2010

(C) The Author(s) 2009. This article is published with open access at Springerlink.com

\begin{abstract}
In this work, the processing steps for producing $440 \mathrm{C}$ stainless steel parts by means of powder injection molding technique were investigated. The molded specimens were debinded by solvent debinding followed by thermal debinding methods and were sintered under vacuum atmosphere. Effective densification took place in the temperature range $1,230-1,240^{\circ} \mathrm{C}$ in the sintering. After heat treatment, specimens sintered at $1,240^{\circ} \mathrm{C}$ for $30 \mathrm{~min}$ had the tensile strength of $876.3 \mathrm{MPa}$, the hardness of $57.7 \mathrm{HRC}$. Pitting mainly occurred in injection molding 440C stainless steel specimens in $\mathrm{NaCl}$ solution. The content of carbon has serious effect on the shape retention. Some methods, such as preventing from oxidation, are presented to avoid the assintered specimens from deformation.
\end{abstract}

Keywords Metal injection molding · Debinding · Sintering · Corrosion resistance $\cdot$ Deformation

\section{Introduction}

The alloy $440 \mathrm{C}$ is a high carbon martensitic stainless steel with moderate corrosion resistance, good strength, and the ability to obtain and keep excellent hardness and wear resistance. Due to excellent properties, $440 \mathrm{C}$ stainless steel has widespread applications, such as Ball bearings and races, gage blocks, molds and dies, knives and measuring instruments $[1,2]$. Powder injection molding (PIM) has become a widely exploited manufacturing technology for the production of near net shaped components [3]. PIM has features of low production cost, shape complexity, tight

D. Li $(\bowtie) \cdot \mathrm{H}$. Hou $\cdot$ L. Liang $\cdot$ K. Lee

State Key Laboratory for Powder Metallurgy,

Central South University,

Changsha, People's Republic of China

e-mail: duxinli6404@yahoo.com tolerances, applicability to several materials and high final properties over conventional production technologies. The low solid content in powder injection molding 440C stainless steel parts usually causes large amount of shrinkage after sintering and thus poor dimensional processes. Rapid sintering densification of $440 \mathrm{C}$ stainless steel powders is possible by exceeding the solidus temperature in an approach termed supersolidus liquid phase sintering. This process is often limited by a narrow processing window for attaining densification without distortion [4]. It also has been reported that the processing of $440 \mathrm{C}$ stainless steels is difficult because of their tendency to form a continuous grain boundary carbide network during sintering and hence, are not generally used for PM applications [5]. All the abovementioned make injection molding 440C steel difficult in both performance and deformation control.

However, metal injection molding $440 \mathrm{C}$ stainless steel is rarely reported. Few efforts have been devoted to understanding the whole process and sintering deformation. Nevertheless, the present work is set out to investigate the various processing parameters, including debinding, sintering temperature, and heat treatment conditions, on the performance and shape retention of 440C stainless steel and to ascertain whether some of the problems encountered during previous research could be successfully overcome.

\section{Experimental}

2.1 Materials and experimental procedures

Gas-atomized 440C stainless steel powders were used in this study. The characteristics of these are given in Table 1 . The powders are largely round in shape as shown in Fig. 1. The multiple-component binder system used was composed of paraffin wax, pure peanut oil, and polyolefin. 
Table 1 The characteristics of the gas-atomized 440C stainless steel powder

Characteristics

Type

Composition

Average particle size

Shape

Pycnometric density

Supplier
Gas-atomized powder

$17.6 \% \mathrm{Cr}, 1.1 \% \mathrm{C}, 0.65 \% \mathrm{Mo}, 0.34 \% \mathrm{Mn}, 0.18 \% \mathrm{Ni}, 0.051 \% \mathrm{O}$, and balance; $\mathrm{Fe}$ $\mathrm{D} 90=20 \mu \mathrm{m}$

Spherical

$7.74 \mathrm{~g} / \mathrm{cm}^{3}$

Ospray
Feedstock was prepared with the powder loading (volume fraction) of $57 \%$. The binder and $440 \mathrm{C}$ stainless steel were mixed at $160^{\circ} \mathrm{C}$ for $2 \mathrm{~h}$ to form a mixture, which was granulated in a single screw squeezing machine to acquire a homogeneous feedstock for injection. The green parts, with the shape shown in Fig. 2, were molded by an injection molding machine.

Debinding was performed in two stages of solvent debinding by methylene dichloride solvent followed by thermal debinding in a vacuum furnace under argon atmosphere, and then sintering was carried out in the same furnace under vacuum atmosphere. The as-sintered specimens were quenched at $1,050^{\circ} \mathrm{C}$ and then tempered at $150^{\circ} \mathrm{C}$ for $2 \mathrm{~h}$. Specimens were immerged in $3.5 \% \mathrm{NaCl}$ solution, which was maintained at $25^{\circ} \mathrm{C}$ for $240 \mathrm{~min}$, in order to study erosion in the presence of chloride ions.

\subsection{Measurement methods}

Density of sintered samples was determined using a water replacement method (Archimedes method). The hardness and strength of the specimens were determined on the hardness tester and the tensile tester, respectively. Microstructures of sintered and heat-treated parts were evaluated with the optical

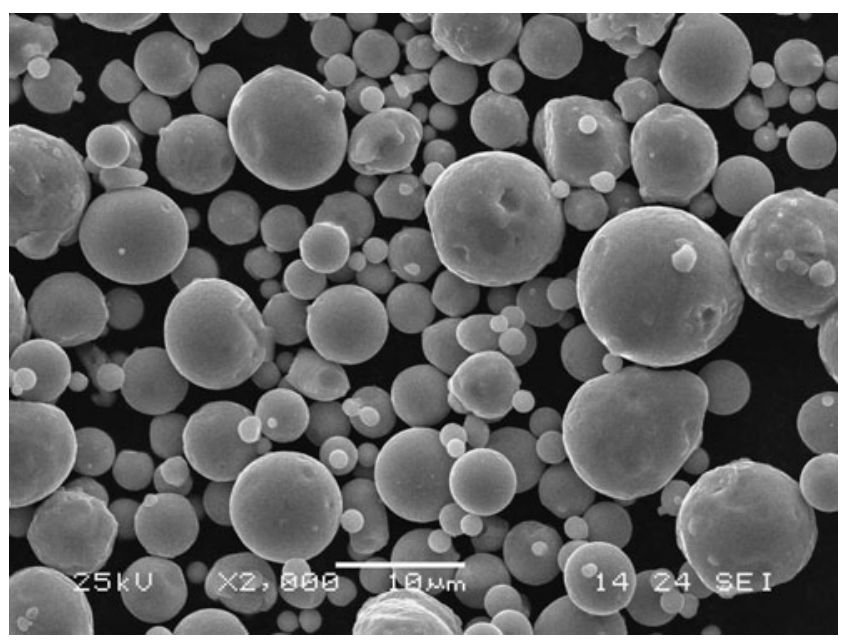

Fig. 1 SEM photograph of the gas-atomized 440C stainless steel powder microscope (Netophot). Morphological analysis of eroded microstructure was carried out using a scanning electron microscope (SEM). The residual carbon and oxygen were determined by $\mathrm{CS} / 44$ and TC/436 analyzer, respectively.

\section{Results and discussion}

\subsection{Debinding}

For safe and rapid binder removal with minimum possibility of cracks and blister formation, solvent debinding followed by thermal debinding was used. Solvent debinding was performed by means of methylene dichloride as a solvent at $37^{\circ} \mathrm{C}$ for $6 \mathrm{~h}$. After solvent debinding, the specimens had good strength, which was enough to be handled easily.

Figure 3 shows that the binder weight loss ratio versus time for the specimens. As it is shown after $6 \mathrm{~h}$, the weight loss ratio is about $62 \%$. Almost wax and oil can be removed. For the specimens with $3.12 \mathrm{~mm}$ thickness, after $1 \mathrm{~h}, 42 \%$ of binder had been removed. It is considered that after removing $40 \%$ of binder, there exists some interconnected capillary porosity inside of the specimen, which makes leaving of gaseous products in subsequent thermal debinding easy in a short time [6]. Hence, the solvent debinding rate can reach $2 \mathrm{~mm} / \mathrm{h}$ through the use of this kind of binder.

The following heating cycle was used for thermal debinding. From room temperature to $200^{\circ} \mathrm{C}$, the temperature increased with heating rate of $3^{\circ} \mathrm{C} / \mathrm{min}$ held at that temperature for $1 \mathrm{~h}$. And from $200^{\circ} \mathrm{C}$ to $385^{\circ} \mathrm{C}$, paraffin wax and oil were removed from the specimen in a low-heating rate of $2^{\circ} \mathrm{C} / \mathrm{min}$ to prevent formation of defects and held at that temperature for

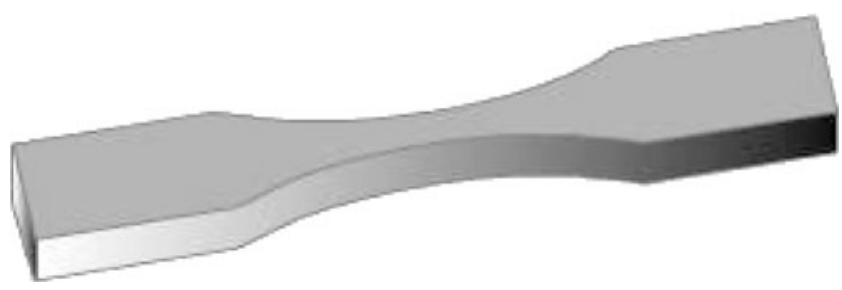

Fig. 2 MIM tensile sample 


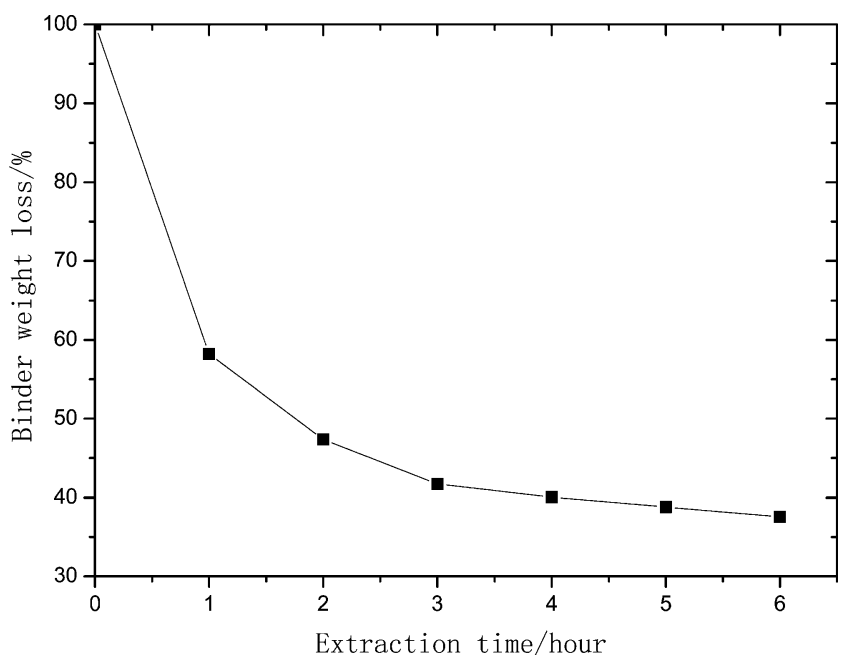

Fig. 3 Rate of weight decreasing of the sample with time in solvent of methylene dichloride at $37^{\circ} \mathrm{C}$

1 h. Next, from $385^{\circ} \mathrm{C}$ to $425^{\circ} \mathrm{C}$, the component of macromolecule began to degrade. The macromolecule was removed with rate of $2^{\circ} \mathrm{C} / \mathrm{min}$ and remained at $425^{\circ} \mathrm{C}$ for $1 \mathrm{~h}$. The following is from $425^{\circ} \mathrm{C}$ to $600^{\circ} \mathrm{C}$ with the rate of $3^{\circ} \mathrm{C} / \mathrm{min}$ and remained at $600^{\circ} \mathrm{C}$ for $30 \mathrm{~min}$ to make sure that the binder was removed completely. Then the temperature increased with $5^{\circ} \mathrm{C} / \mathrm{min}$ to $950^{\circ} \mathrm{C}$ to finish presintering.

Figure 4 shows scanning electron micrograph of a debinded specimen cross section. As can be seen, nearly all the binder has been removed from the specimen and sintering neck has formed to keep the shape.

\subsection{Sintering}

To understand how sintering temperatures and the phases present during sintering influence the sintered densities,

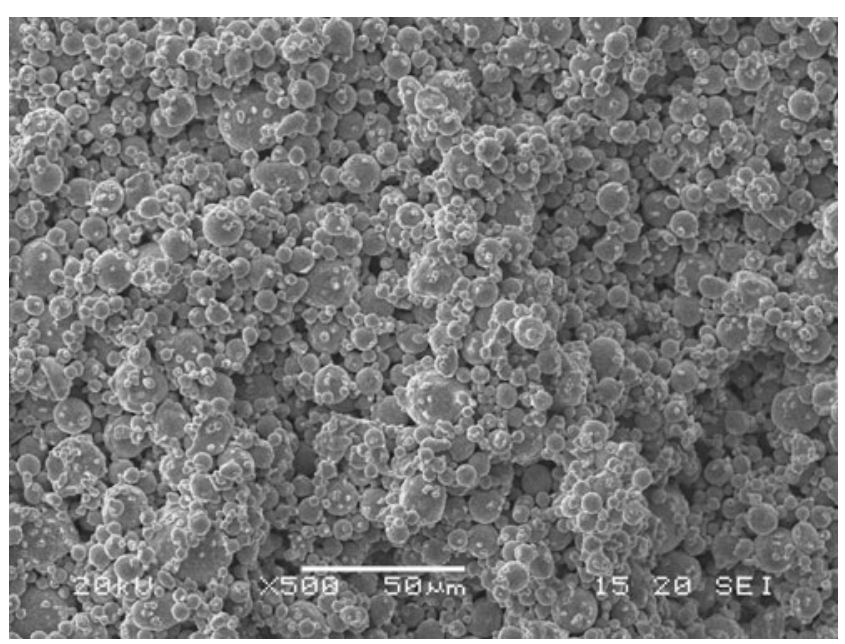

Fig. 4 Scanning electron micrograph of a debinded specimen at $950^{\circ} \mathrm{C}$

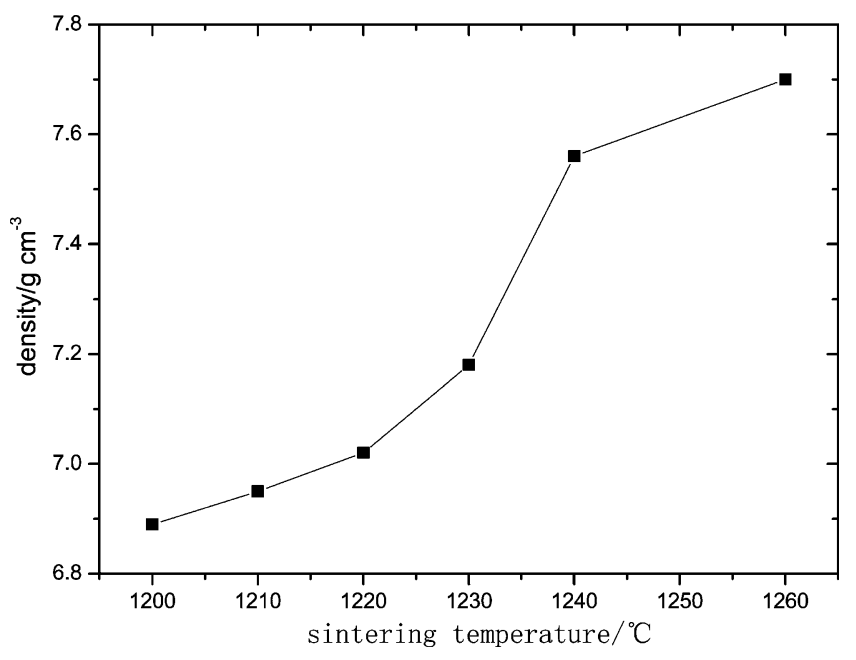

Fig. 5 Effect of sintering temperature on final density

440C stainless steel specimens were sintered under vacuum from $1,200^{\circ} \mathrm{C}$ to $1,260^{\circ} \mathrm{C}$ for $30 \mathrm{~min}$. Figure 5 shows that the sintered density increased from 6.89 to $7.56 \mathrm{~g} / \mathrm{cm}^{3}$ when sintering temperature increase from $1,200^{\circ} \mathrm{C}$ to $1,260^{\circ} \mathrm{C}$. Effective densification took place in the temperature range of $1,230-1,260^{\circ} \mathrm{C}$. Densification rates at temperatures below approximately $1,220^{\circ} \mathrm{C}$ were consistent with solid state diffusion and were extremely low, but only liquid phases began to appear; the densification rate accelerated rapidly. These results are very possibly related to the presence of the liquid phase at high temperatures. There is an optimal maximum sintering temperature that relates to the volume fraction of liquid. This is in turn on the alloy composition. For 440C stainless steel, every little increase in temperature increases a large amount of liquid. Around the optimum temperature is a narrow range of acceptable sintering temperatures that is about $10 \mathrm{~K}$ wide [7]. If a small quantity of liquid forms, then there is poor densification because the specimen has too much solid-solid contact. However, temperatures in excess of the optimal range results in grain growth, slumping, nonuniform densification, pore coalescence, and swelling.

Figure 6 showed the microstructure of specimens sintered at different temperatures. At sintering temperature of $1,210^{\circ} \mathrm{C}$ (Fig. 6a), there were still a number of spheroidal pores visible throughout the sample, indicating that sintering had not gone to completion. When temperature was increased to $1,230^{\circ} \mathrm{C}$ (Fig. 6b), there was a reduction in the size of the pores and moderate increase in grain size. At $1,260^{\circ} \mathrm{C}$ (Fig. 6c), there was a marked difference in the microstructure. An abrupt increase in grain size was observed with the morphology of the carbide changing to a largely continuous grain boundary network. 

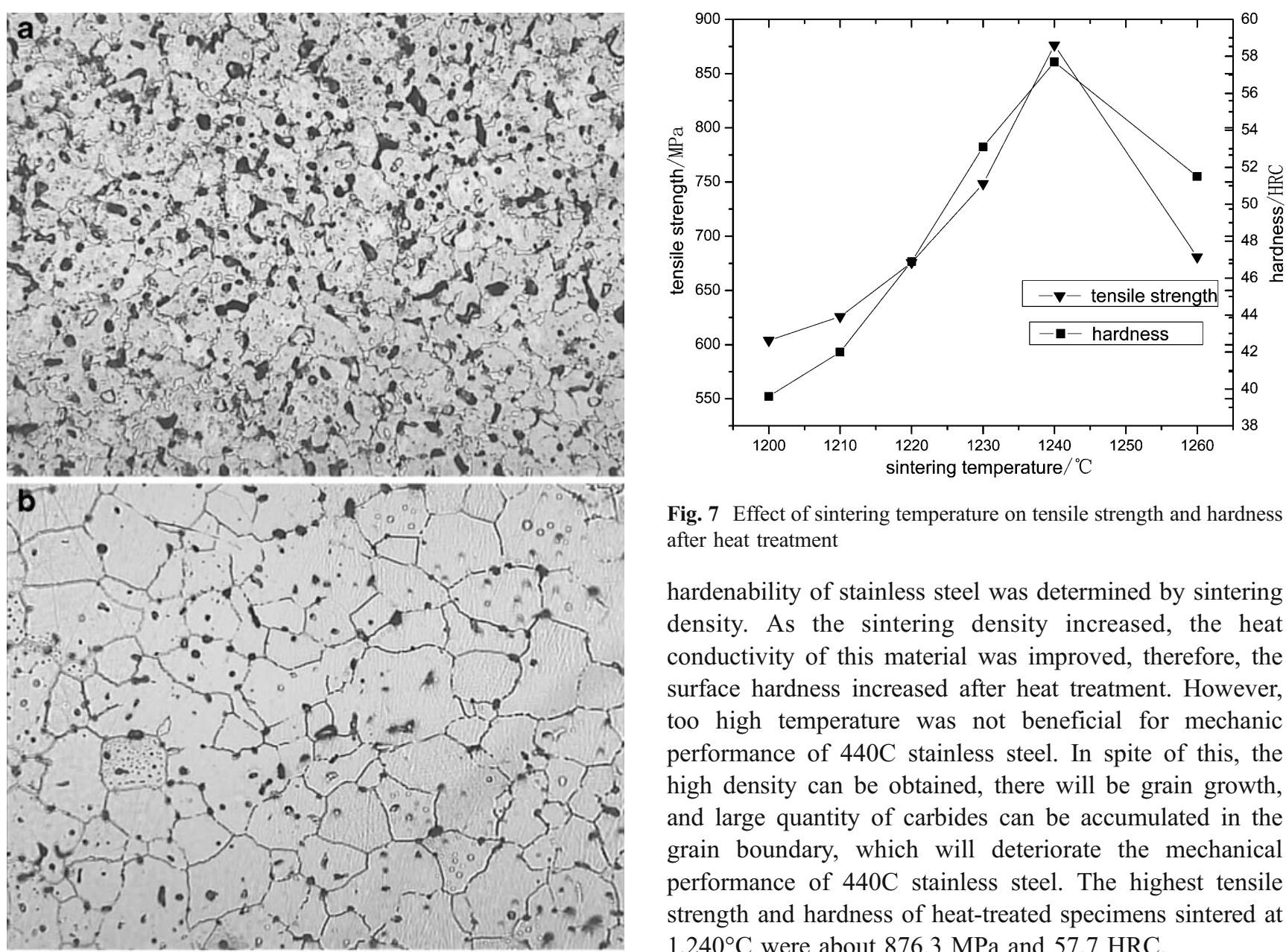

Fig. 7 Effect of sintering temperature on tensile strength and hardness after heat treatment

hardenability of stainless steel was determined by sintering density. As the sintering density increased, the heat conductivity of this material was improved, therefore, the surface hardness increased after heat treatment. However, too high temperature was not beneficial for mechanic performance of $440 \mathrm{C}$ stainless steel. In spite of this, the high density can be obtained, there will be grain growth, and large quantity of carbides can be accumulated in the grain boundary, which will deteriorate the mechanical performance of $440 \mathrm{C}$ stainless steel. The highest tensile strength and hardness of heat-treated specimens sintered at $1,240^{\circ} \mathrm{C}$ were about $876.3 \mathrm{MPa}$ and $57.7 \mathrm{HRC}$.

Figure 8 shows that the heat-treated specimens were composed of martensite, retained austenite, and carbides. However, the carbide had become spherical and finely dispersed throughout the grain boundary and the matrix. It will form a continuous gain boundary network when sintered at high temperatures. Continuous grain boundary carbide net-

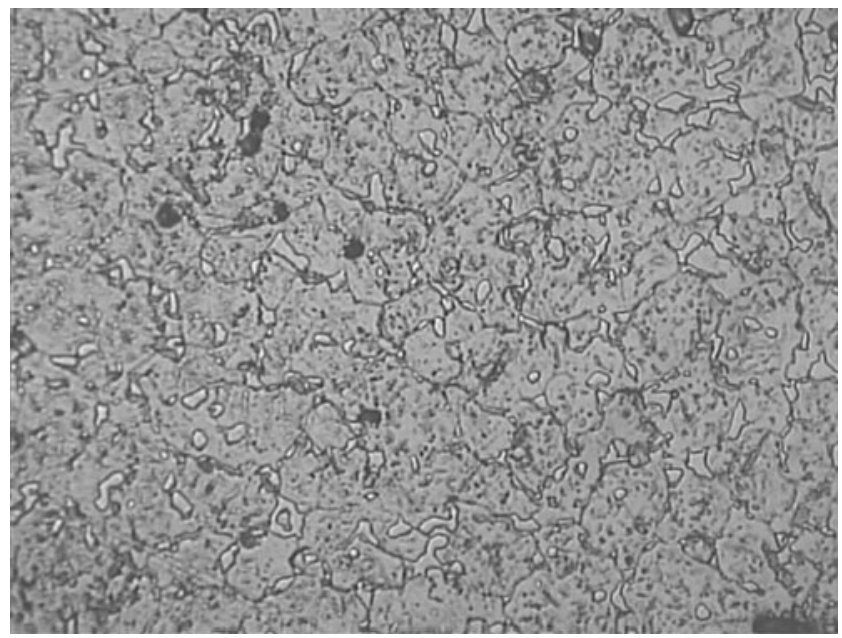

Figure 7 shows the average tensile strength and hardness of sintered parts under different sintering temperatures after heat treatment. From $1,200^{\circ} \mathrm{C}$ to $1,240^{\circ} \mathrm{C}$, the performance increased with the increase of sintering temperature because

Fig. 8 Microstructure of specimens sintered at $1,230^{\circ} \mathrm{C}$ after heat treatment 


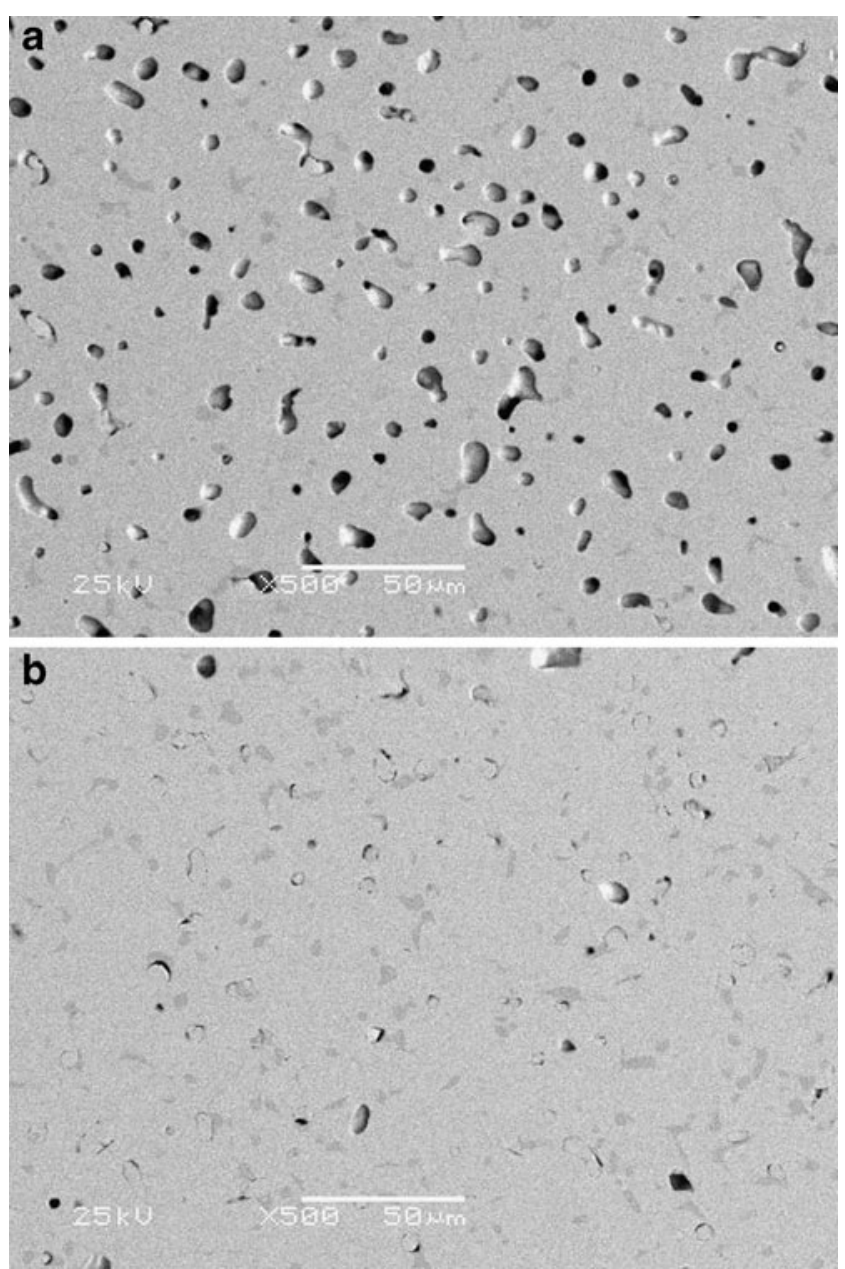

Fig. 9 Backscattered electron image of stainless samples sintered at different temperatures. a $1,210^{\circ} \mathrm{C}$. b $1,240^{\circ} \mathrm{C}$ work is difficult to vanish even after heat treatment; this would have a very deleterious effect on the toughness of material.

\subsection{Corrosion resistance}

The SEM micrographs in Fig. 9 clearly reveal the large difference in the degree of corrosion between specimens sintered at $1,210^{\circ} \mathrm{C}$ and at $1,240^{\circ} \mathrm{C}$. Pitting was mainly exit in injection molding $440 \mathrm{C}$ stainless steel specimens in $\mathrm{NaCl}$ solution. When sintering temperature was higher, the corrosion in the specimens was slighter. The phenomenon depends on the material (with the pore features). The density increased with the increase of sintering temperature. It is obvious that there are fewer pores which are small and spherical due to shrinkage and high sintering temperature. Compared to lower temperature sintering, it was effective to prevent from corrosion by $\mathrm{NaCl}$ for less area contacting with the solution.

Precipitation of carbide is one of the reasons for deterioration of $440 \mathrm{C}$ stainless steel corrosion resistance after tempering. It was related to lacking of chromium $(\mathrm{Cr})$ if there was precipitation of carbide. Figure 10 illustrates that carbide was to separate out from retained austenite matrix after tempering at $150^{\circ} \mathrm{C}$, the areas lacking of $\mathrm{Cr}$ were corroded priority, therefore, pitting was formed.

\subsection{Effect of carbon content on shape retention}

Sintering action was heavily influenced by content and distribution of carbon. The carbon has been found to decrease the liquid temperature and to enhance the sintering kinetics. In the same sintering temperature, the quantity of liquid was influenced by the content of carbon. More carbon means more liquid in the sintering. Furthermore, the dissolved carbon changes the surface tension and viscosity of the steel melt
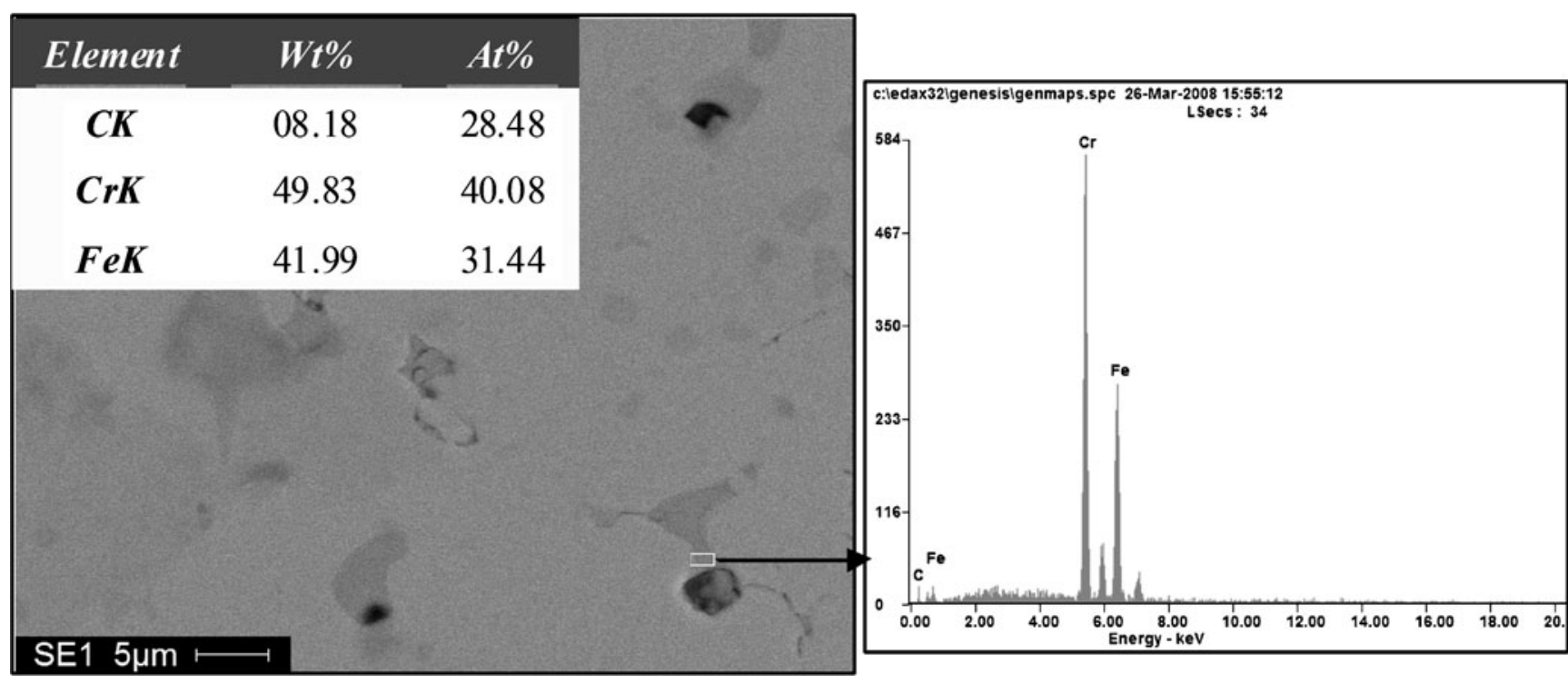

Fig. 10 Energy spectrum analysis of corrosion in the sample microstructure 
Table 2 Carbon and oxygen content of $440 \mathrm{C}$ stainless steel in the process and its sintering deformation

\begin{tabular}{|c|c|c|c|c|}
\hline & Condition & $\begin{array}{l}\text { Content of carbon } \\
(\%)\end{array}$ & $\begin{array}{l}\text { Content of oxygen } \\
(\%)\end{array}$ & $\begin{array}{l}\text { Situation of } \\
\text { deformation }\end{array}$ \\
\hline Powder & Sealed & 1.1 & 0.073 & \\
\hline \multirow{4}{*}{$\begin{array}{l}\text { Debinding } \\
\text { specimens }\end{array}$} & Laid in the air & 1.07 & 0.33 & - \\
\hline & Deoxidation in $\mathrm{H}_{2}$ & 1.05 & 0.092 & \\
\hline & Sealed in the vacuum & 1.07 & 0.086 & \\
\hline & Use in the binding specimens laid in the air & 0.86 & 0.0043 & Serious deformation \\
\hline \multirow{2}{*}{$\begin{array}{l}\text { Sintering } \\
\text { specimens }\end{array}$} & Use the debinding specimens deoxidizedin $\mathrm{H}_{2}$ & 1.04 & 0.0069 & No deformation \\
\hline & $\begin{array}{l}\text { Use the debinding specimens sealed in the } \\
\text { vacuum }\end{array}$ & 1.06 & 0.0052 & No deformation \\
\hline
\end{tabular}

significantly. All these affect the instability of stainless steel melt. J. Liu et al. [8] found that a liquid film provides a viscous resistance to grain movement and contributes to the rigidity of the structure during SLPS; the microstructural softening parameter $\zeta$ was influenced by quantity of liquid. Therefore, variety of content of carbon will decrease dimensional tolerances; the variety may even lead to sintering deformation by influencing the quantity and viscosity of liquid.

Table 2 showed carbon and oxygen content of 440C stainless steel in each process. The content of carbon of specimens debinding in $\mathrm{H}_{2}$ atmosphere is slightly lower than that of powder. It was found that the content of carbon and oxygen was both reduced after sintering. It indicated that there was a reaction between $\mathrm{C}$ and $\mathrm{O}$ in the sintering. $\mathrm{Cr}_{2} \mathrm{O}_{3}$, which will retard the forming of sintering neck, was produced by reaction of $\mathrm{O}$, and $\mathrm{Cr}$. H. Ohtsubo [9] and Yunxin Wu et al. [10] found that densification of stainless steel was started approximately at $900^{\circ} \mathrm{C}$. Meanwhile, between $900^{\circ} \mathrm{C}$ and $1,100^{\circ} \mathrm{C}$, the densification became faster. If the specimens were laid in the air for several days, the content of oxygen increased to $0.33 \%$ and deformation happened in sintering. Oxidation-reduction reaction consumed the content of carbon and makes the carbon distribution nonuniform. Therefore, nonuniform distribution of liquid formed in the sintering lead to sintering deformation for nonuniform shrinkage. The sintering deformation can be avoided by deoxidation in $\mathrm{H}_{2}$ if the product was already oxidation.

\section{Conclusions}

From the results of the present investigation, the following conclusions can be made. The debinding of injectionmolded specimens with wax/oil-based binder using a solvent and thermal debinding method can result in a defect-free specimen. For vacuum sintering of injection molded 440C stainless steel, effective densification took place in the temperature range $1,230-1,240^{\circ} \mathrm{C}$. Sintering at too high a temperature will result in a rapid grain growth, slumping, nonuniform densification, pore coalescence, and swelling.
After heat treatment, the microstructure of injection molding $440 \mathrm{C}$ stainless steel consisted of martensite, residual austenite, carbide, and specimens sintered at $1,240^{\circ} \mathrm{C}$ for30 $\mathrm{min}$ have the tensile strength of $876.3 \mathrm{MPa}$, the hardness of 57.7 HRC. Pitting was mainly exit in injection molding 440C stainless steel specimens in $\mathrm{NaCl}$ solution.

The content of carbon has heavily effect ion on the shape retention. Some methods, such as preventing from oxidation, are presented to avoid the as-sintered specimens from deformation.

Open Access This article is distributed under the terms of the Creative Commons Attribution Noncommercial License which permits any noncommercial use, distribution, and reproduction in any medium, provided the original author(s) and source are credited.

\section{References}

1. John Sedriks A (1979) Corrosion of stainless steels. Wiley, New York

2. Li MQ, Ji SC (1997) Research of High-carbon stainless steel as pump and valve material I: effect of heat-treatment on material's micro-structure and performance. Journal of Lanzhou University (Natural Sciences) 33(4):53-59

3. Michaeli W, Opfermann K, Kamps T (2007) Int J Adv Manuf Tech 33:206-211

4. German RM (1990) Supersolids liquid phase sintering part I: process review. IJPM 26(1):23-34

5. Newel MA, Davies HA, Messer PF, Greensmith DJ (2005) Metal injection moulding of scissors using hardenable stainless steel powders. Powder Metal 48(3):227-230

6. Li Y, Jiang F, Zhao L, Huang B (2003) Critical thickness in binder removal process for injection molded compacts. Mater Sci Eng A362(1-2):292-299

7. Wohlfromml H (2002) Powder injection molding stainless steelproduce process, performance, application. Powder Metallurgy 12 (4):7-15

8. Liu J, Lal A, German RM (1999) Densification and shape retention in supersolidus liquid phase sintering[J]. Acta Mater 47(18):4615-4626

9. Ohtsubo H, Maruta K, Nishimura K, Makiishi Y (1992) Deformation behavior of metal injection molded compacts during sintering [A], Powder injection molding symposium-[C], Princeton: Powder Industries Federation, pp 409-417

10. Wu YX, Blaine D, Marx B, Schlaefer C, German RM (2002) Sintering densification and microstructure evolution of injection molding grade $17-4 \mathrm{PH}$ stainless steel powder. Metallurgical and materials transactions A 33A(July):2185-2194 